\title{
TESIS DOCTORALES DIRIGIDAS
}

BOX AMORÓS, MARGARITA (1985): Las zonas húmedas de la provincia de Alicante y los procesos de intervención antrópica.

VERA REBOLLO, JOSÉ FERNANDO (1986): Turismo y urbanización en el litoral alicantino.

PONCE HERRERO, GABINO JOAQUÍN (1986): El corredor de Almansa. Estudio Geográfico.

DE VERA FERRE, JESÚS RAFAEL (1986): La formación y la situación actual de la red de carreteras de la provincia de Alicante.

BRÚ RONDA, CONCEPCIÓN (1986): Recursos, usos y economía del agua en la provincia de Alicante.

MARCO MOLINA, JUAN ANTONIO (1989): El medio físico de Aitana.

HERNÁNDEZ HERNÁNDEZ, MARÍA (1996): Los espacios agrarios tradicionales de la provincia de Alicante: evolución e impactos ambientales.

TORRES ALFOSEA, FRANCISCO JOSÉ (1996): Usos turísticos y dominio público marítimo-terrestre. Realidad y ordenación en la Costa Blanca.

GIMÉNEZ FONT, PABLO (2006): Ordenación del territorio y transformaciones paisajísticas en el Setecientos Valenciano. 